\title{
ОБРАЗОВАТЕЛЬНАЯ УСЛУГА КАК СОЦИАЛЬНО-ЭКОНОМИЧЕСКАЯ КАТЕГОРИЯ
}

\author{
(c) 2020 Демина Светлана Александровна \\ кандидат экономических наук, доцент \\ доцент кафедры экономической теории и менеджмента \\ Московский педагогический государственный университет (МПГУ), Россия, Москва \\ Email: sa.demina@mpgu.su \\ (c) 2020 Бекетова Ольга Николаевна \\ доктор экономических наук, профессор \\ профессор кафедры бизнес-технологий и управления \\ МИРЭА - Российский технологический университет, Россия, Москва \\ (c) 2020 Кожукалова Оксана Юрьевна \\ кандидат экономических наук, доцент \\ доцент кафедры экономической теории и менеджмента \\ Московский педагогический государственный университет (МПГу), Россия, Москва \\ Email: o.kozhukalova@mpgu.su \\ (c) 2020 Демин Александр Сергеевич \\ Начальник отдела информационно-образовательных систем \\ Московский педагогический государственный университет (МПГУ), Россия, Москва \\ Email: as.demin@mpgu.su
}

В статье рассмотрены подходы, с разных сторон характеризующие образовательные услуги. Выявлены и систематизированы отличительные особенности образовательной услуги как социальноэкономической категории, определены основные направления развития системы оценки качества современного образования.

Ключевые слова: образование, услуга, благо, эффективность, качество

Право на получение образования является важнейшим социальным правом человека. Если подходить к осмыслению понятия «образование» в категориях прав собственности, то особый интерес представляет то, что в Законе «Об образовании в Российской Федерации» (далее Закон Об образовании) образование рассматривается как процесс, являющийся общественно значимым благом [1].

Очевидно, что образование можно рассматривать как общественное благо поскольку потребность в образовании имеется не у отдельной части, а у всего населения страны. В силу того, что практически невозможно исключить человека из круга потребителей данного блага, образование характеризуется признаком неисключения. Признак несоперничества в потреблении образования проявляется в том, что получение образования одним человеком не уменьшает возможностей потребления его другим.

В Законе Об образовании прямо указаны потребители процесса обучения: человек, се- мья, общество и государство. Это связано с тем, что образование как благо нельзя разложить на отдельные единицы. В новой редакции Закона Об образовании образование предстает не как процесс получения бессистемных знаний, а совокупность знаний, умений, навыков и практического опыта.

Вместе с тем, образование нельзя отнести к категории чистого общественного блага. Необходимо заметить, что в Российской Федерации гарантируются общедоступность и бесплатность дошкольного, начального общего, основного общего и среднего общего образования, среднего профессионального образования, а также доступность на конкурсной основе бесплатного высшего образования, в том случае если образование данного уровня гражданин получает впервые (Пункт 3 статьи 5 Закона).

В пункте 4 статьи 5 Закона Об образовании указано, что реализация права каждого человека на образование обеспечивается путем создания федеральными государственными органа- 
ми, органами государственной власти субъектов Российской Федерации и органами местного самоуправления соответствующих социальноэкономических условий для его получения, расширения возможностей удовлетворять потребности человека в получении образования различного уровня и направленности в течение всей жизни. В такой трактовке образование является скорее благом совместного потребления с такими характеристиками как избирательность, альтернативность использования и убывание потребления данного блага. Может ли это значить, что образование как благо является в тоже время объектом купли-продажи?

Для ответа на этот вопрос обратимся к пункту 1 статьи 101 Закона Об образовании, где сказано, что организации, осуществляющие образовательную деятельность, вправе осуществлять указанную деятельность за счет средств физических и (или) юридических лиц по договорам об оказании платных образовательных услуг. Платные образовательные услуги представляют собой осуществление образовательной деятельности по заданиям и за счет средств физических и (или) юридических лиц по договорам об оказании платных образовательных услуг. Далее, в статье 101 указано на то, что «доход от оказания платных образовательных услуг используется указанными организациями в соответствии с уставными целями» [2].

Таким образом, сама терминология Закона Об образовании вскрывает двойственную природу образования, являющегося одновременно благом и услугой. Встает вопрос, что же все таки собой должно представлять образование: услугу, предоставляемую на конкурентной основе и за плату, или социально значимое благо, гарантируемое государством? Отвечая на этот вопрос важно также определить место современных информационных технологий в процессе повышения открытости и доступности образования, поскольку именно информационно-образовательные технологии рассматриваются сегодня в качестве основного средства повышения доступности образования для всех слоев населения.

Особой неоднозначностью характеризуется именно дистанционная образовательная услуга. С одной стороны, дистанционное образование является наиболее перспективным и быстро развивающимся направлением рынка образовательных услуг, и его роль в формировании интеллектуального потенциала общества в бу- дущем достаточно велика, а отнесение его к категории насущных или даже общественных благ, очевидно. Следовательно, услуги дистанционного образования должны рассматриваться как общественные или специальные образовательные услуги. С другой стороны, дистанционные услуги сферы образования скорее являются особыми образовательными услугами и зачастую принимают вид частного блага.

С представленной позиции услуги дистанционного образования могут выступать как общественные блага, в том случае если доступ к ним неограничен, а могут выступать средством удовлетворения конкретного индивидуума - частным благом, когда они предоставляются только тем, кто за них заплатил.

Дискуссии вокруг образования, его содержания и функций носят острый характер среди научного сообщества. Во многом это обусловлено тем, что сама категория «образование» не позволяет выделить специфические особенности действий или деятельности по оказанию услуги образования. К настоящему времени разработаны и накоплены литературные, социологические и статистические материалы, позволяющие вскрыть суть рассматриваемой проблемы. Приведем мнения авторов по вопросу определения понятия «образовательная услуга».

О. Кивенен и Р. Рияне характеризуют образовательную услугу как «тот или иной объем учебной или научной информации, передаваемой субъекту в виде суммы знаний общеобразовательного и специального характера, а также практических навыков для последующего применения» [3].Этот подход был отражен в первоначальной редакции Федерального закона от 29.12.2012 № 273-Ф3 «Об образовании в Российской Федерации», где в узком значении сохранялось понятие образовательной услуги как объема учебной и научной информации, передаваемой гражданину в виде суммы знаний общеобразовательного и специального характера и практических навыков для последующего применения [4].

Системный характер знаний и информации отражен в определениях В.П. Щетинина и С.А. Зайчиковой: «образовательная услуга - система знаний, информации, умений и навыков, которые используются в целях удовлетворения разнообразных образовательных потребностей личности, общества, государства [5].

Зайчикова С.А. в своих работах подчеркивает, что образовательные услуги как система зна- 
ний, умений и навыков, используются в целях удовлетворения потребностей индивида, общества и государства и направлены на приращение человеческого капитала [6].

По мнению К.В. Величковича образовательная услуга является экономической категорией и выражает отношения, которые складываются между ее субъектами - школой, учащимися, государством и работодателем - по поводу воспроизводства системы знаний, умений, навыков и компетенций, необходимых для нормального функционирования рабочей силы [7].

А.А. Стрижов характеризует образовательную услугу как целенаправленную деятельность, характеризуемую взаимодействием участников образовательного процесса и направленную на удовлетворение образовательных потребностей личности [8]. Данная характеристика созвучна понятию услуги, которое можно обнаружить в п. 5 ст. 38 Налогового кодекса РФ, где услугой признаётся деятельность, результаты которой не имеют материального выражения, реализуются и потребляются в процессе этой деятельности [9].

В.В. Чекмарев определяет образовательную услугу как продукт образовательного производства и процесс, в котором создается человеческий капитал через индивидуальное потребление трудового потенциала производителя и индивидуальное производство трудового потенциала потребителя [10].

А.Б. Вифлеемский полагает, что сущность образовательных услуг состоит в передаче знаний новым индивидам, причем «...объем знаний, как продукт деятельности образовательного комплекса, потенциально безграничен» [11].

В исследованиях Сыроваткиной Т.Н. образовательная услуга выступает как продукт специфического интеллектуального труда. При этом автор подчеркивает, что с позиции интеграции в мировое рыночное пространство образовательная услуга выступает как объект коммерческих отношений, а возрастающая стоимость образовательной услуги не исчезает в момент потребления и не зависит от времени потребления [12].

Рассмотренные определения с разных сторон характеризуют образовательные услуги. Ряд авторов представляет это понятие как определенный объем информации, другая часть научного сообщества - как систему знаний, третья часть авторов определяет образовательную услугу как особый вид деятельности, четвертные - как систему отношений, пятые определяют образовательную услугу как продукт образовательного производства.

В соответствии с главным аспектом, на котором был сделан акцент, определения понятия «образовательная услуга» были сведены в таблицу.

Таблица 1. Различные аспекты в определении понятия «образовательная услуга»

\begin{tabular}{|l|l|}
\hline \multicolumn{1}{|c|}{ Главный аспект } & \multicolumn{1}{c|}{ Определение } \\
\hline Информация и знания & $\begin{array}{l}\text { Тот или иной объем учебной или научной информации, передаваемый субъекту } \\
\text { в виде суммы знаний общеобразовательного и специального характера, а также } \\
\text { практических навыков для последующего применения (О. Кивенен, Р. Рияне) }\end{array}$ \\
\hline Система знаний & $\begin{array}{l}\text { Система знаний, информации, умений и навыков, которые используются в целях } \\
\text { удовлетворения разнообразных образовательных потребностей личности, обще- } \\
\text { ства, государства (В.П. Щетинина). } \\
\text { Система знаний, умений и навыков, которые используются в целях удовлетворе- } \\
\text { ния потребностей индивида, общества и государства и направлены на приращение } \\
\text { человеческого капитала (С.А. Зайчикова). }\end{array}$ \\
\hline Вид деятельности & $\begin{array}{l}\text { Образовательная услуга - целенаправленная деятельность, характеризуемая взаи- } \\
\text { модействием участников образовательного процесса и направленная на удовлетво- } \\
\text { рение образовательных потребностей личности (А.А. Стрижов). }\end{array}$ \\
\hline Отношения & $\begin{array}{l}\text { Образовательная услуга, как экономическая категория, выражает отношения, } \\
\text { которые складываются между ее субъектами - школой, учащимися, государством } \\
\text { и работодателем - по поводу воспроизводства системы знаний, умений, навыков } \\
\text { и компетенций, необходимых для нормального функцонирования рабочей силы } \\
\text { (К.В. Величкович). }\end{array}$ \\
\hline Продукт & $\begin{array}{l}\text { Сущность образовательных услуг состоит в передаче знаний новым индивидам, } \\
\text { причем объем знаний, как продукт деятельности образовательного комплекса, } \\
\text { потенциально безграничен (А.Б. Вифлеемский) } \\
\text { Образовательная услуга - продукт специфического интеллектуального труда } \\
\text { (Т.Н. Сыроваткина). }\end{array}$ \\
\hline Процесс & $\begin{array}{l}\text { Образовательная услуга одновременно является продуктом образовательного } \\
\text { производства, а также выступает как процесс, в котором создается человеческий ка- } \\
\text { питал через индивидуальное потребление трудового потенциала производителя и } \\
\text { индивидуально производство трудового потенциала потребителя (В.В. Чекмарев). }\end{array}$ \\
\hline
\end{tabular}


Несмотря на различия во взглядах авторов на предмет изучения, общим является то, что в условиях рыночной экономики образовательная услуга является специфическим товаром. Однако, в отличие от обычного товара, представленного на рынке, она имеет свои отличительные особенности.

Во-первых, образовательная услуга характеризуется усвоенным объемом знаний, умений, навыком и компетенций отвечающих требованиям федеральных государственных образовательных стандартов и требованиям рынка труда. При этом, получение высшего образования является способом удовлетворения разнообразных потребностей самой личности обучающегося: в самореализации, профессиональном росте и т.д. Эти потребности обладают определенным уровнем стабильности вне зависимости от изменений конъюнктуры рынка труда и уровня его развития. Поэтому потребность в образовательных услугах отличается своей стабильностью.

Во-вторых, эффективность процесса предоставления образовательных услуг обусловлена как качеством деятельности образовательного учреждения, так и качеством деятельности ее обучающегося, то есть потребителя услуги. Это существенным образом отличает образовательную услугу от других услуг, качество предоставления которых не зависит от деятельности объекта оказания этих услуг. Поэтому процесс обучения представляет не столько процесс накопления самих услуг, сколько их результатов, а характер отношений, складывающихся в процессе обучения, носит субъект-субъектный характер.

В своих исследованиях Скоробогатова Ю.А. приходит к выводу о том, что образовательные услуги обладают общими свойствами, характерными для всех услуг. При этом, применительно к образовательным услугам автор выделяет следующие специфические черты: возможность потребления образовательной услуги только в процессе ее оказания; неэквивалентный характер услуги и результата ее потребления; творческий характер процесса потребления; возможность коллективного потребления; способность изменять потребителя; эридитарность [13].

Еникеева С.Д. подчеркивает, что образовательные услуги обладают специфическими чертами, которые обусловлены особенностями экономики образования как отрасли социальной сферы. Среди специфических особенностей образовательной услуги автор выделяет: социальную значимость; крупномасштабность; уникальность сферы образования; дифференциацию образовательных услуг по видам подготовки; специфику государственного регулирования в сфере образования, определяющую особенности образовательных услуг [14].

Можно сделать вывод о том, что образовательная услуга как социально-экономическая категория, представляет собой специфический вид товара, представленный в виде структурированной совокупности информации и знаний, а также направленный на приобретение профессиональных знаний, умений и навыков для их последующего применения в практической деятельности, на всестороннее, в том числе и интеллектуальное, развитие личности. При этом любая образовательная услуга может быть предоставлена только в присутствии заказчика и при его участии, а качество ее предоставления будет зависеть от активности потребителя в процессе ее получения.

В этой связи, хотелось бы отметить, что в текущей редакции Федерального закона «Об образовании в Российской Федерации» в статье второй представлено тридцать четыре понятия, характеризующих отношения в сфере образования. Однако среди них нет такого понятия как образовательная услуга.

Отсутствие в новой редакции Закона Об образовании понятия «образовательная услуга» вызывает ряд коллизий, связанных, в том числе, с возмездным характером деятельности самого преподавателя. Так, в Законе Об образовании конфликт интересов педагогического работника (п. 33) определяется как «ситуация, при которой у педагогического работника при осуществлении им профессиональной деятельности возникает личная заинтересованность в получении материальной выгоды или иного преимущества...». В такой трактовке складывается впечатление, что качество обучения не зависит от размера и формы оплаты труда педагога.

Вместе с тем, педагог является таким же субъектом социально-трудовых отношений как и любой работник, а само по себе наличие рынка платных образовательных услуг автоматически делает педагога полноценным участником этого рынка.

А.В. Антонова в своей работе отмечает, что введение понятия «образовательные услуги» в развитие образовательного законодательства позволило узаконить платные формы образова- 
ния и расширить тем самым возможности финансирования государственных и муниципальных образовательных учреждений [15].

Кроме образовательных услуг, в полной мере соответствующих образовательным программам и государственным образовательным стандартам, а также дополнительных образовательных услуг, не предусмотренных соответствующими образовательными программами и государственными стандартами, Антонова выделяет сопутствующие услуги. Сопутствующие услуги способствуют удовлетворению бытовых и культурных потребностей студентов и профессорско-преподавательского состава, влияют на качество обучения в целом, хотя и не сопряжены непосредственно с образовательным процессом.

Важно отметить, что в соответствии с действующим законодательством, образовательные учреждения могут быть созданы только в форме, установленной гражданским законодательством для некоммерческих организаций, а полученная некоммерческой организацией прибыль не подлежит распределению между участниками (членами) некоммерческой организации. При этом доход от оказания платных образовательных услуг должен использоваться указанным учреждением в соответствии с уставными целями. Это означает, что труд преподавателя является, не столько статьей расходов, сколько целью оказания платных образовательных услуг, потому что именно деятельность преподавателя опосредует учебный процесс.

Преподаватель является носителем тех знаний, которые реализуются в ходе образовательного процесса. С такой позиции некорректно говорить о конфликте интересов педагогического работника как о личной заинтересованности преподавателя в получении материальной выгоды, поскольку затраты на оплату труда педагога выступаю как инвестиция в капитал данной образовательной организации.

Важно обратить внимание еще на один аспект образовательной деятельности - воспитание. Принципиальное отличие новой редакции Закона Об образовании стоит в том, что образование раскрыто как целенаправленный процесс воспитания и обучения. Соответственно функция преподавателя в образовательном процессе состоит не только в обучении, но и воспитании, а значит, статус преподавателя не может быть сведен до уровня служащего, оказы- вающего определенный набор услуг заказчику.

В высшей школе (также как и в общеобразовательной) реализуются элементы физического, нравственного, политического, трудового и эстетического воспитания. В зависимости от направленности образовательного учреждения превалируют те или иные виды воспитательной работы. Без этих составляющих образовательная деятельность будет носить характер подготовки, а не образования.

Без своей воспитательной функции высшее образование превратится в процесс приобретения конкретных навыков. Между тем, именно высшее образование отличается от ремесла наличием широкого образа мышления, широких знаний о мире, способности понимать и интерпретировать действительность исходя из устоявшихся морально-этических позиций человека. В этом смысле образование не может рассматриваться исключительно как набор услуг.

В то же время, в образовании есть тенденция, которую можно назвать предоставлением услуг, поскольку человека надо научить писать, считать, то есть предоставить ему некий набор знаний. При этом для реализации образовательного процесса требуется оказать ряд сопутствующих услуг, связанных с организацией питания и удовлетворения других бытовых и культурных потребностей студентов и профессорскопреподавательского состава. Эти услуги могут быть разного качества и стоимости. Следовательно, возникает естественная для рынка ценовая сегментация.

Если обратиться к ст. 779 ГК РФ, то в определении договора возмездного оказания услуг можно обнаружить указание на услуги как действия или деятельность. По договору возмездного оказания услуг исполнитель обязуется по заданию заказчика оказать услуги (совершить определенные действия или осуществить определенную деятельность), а заказчик обязуется оплатить эти услуги [16]. Одновременно с этим, общественно значимое благо, напротив, гарантируется государством на началах равенства и исключает ценовую конкуренцию.

Различия в подходах к образованию как к социально значимому благу и услуге затрагивают как понимание целей, задач, функций и его содержания (Таблица 2).

Обобщая сказанное, можно сделать следующие выводы.

1. Образование это - единый целена- 
Таблица 2. Конструкты образования в разных идеологических подходах

\begin{tabular}{|c|c|c|}
\hline Конструкты & Образование как социально значимое благо & Образование как услуга \\
\hline Цели & Развитие личностного потенциала & Усвоение знаний \\
\hline Задачи & $\begin{array}{l}\text { Формирование и развитие тех способностей, } \\
\text { которые нужны обучающемуся и обществу }\end{array}$ & $\begin{array}{l}\text { Формирование и развитие знаний, умений и } \\
\text { навыков }\end{array}$ \\
\hline Функции & $\begin{array}{l}\text { Использование ранее накопленной культуры } \\
\text { в целях воспитания индивида, развития его } \\
\text { творческих способностей }\end{array}$ & $\begin{array}{l}\text { Формирование социально-профессиональ- } \\
\text { ной структуры общества, где люди способны } \\
\text { осваивать научные и технические новшества } \\
\text { и эффективно использовать их в профессио- } \\
\text { нальной деятельности }\end{array}$ \\
\hline Содержание & $\begin{array}{l}\text { Система мировоззренческих, нравственно- } \\
\text { эстетических идей, элементы социального, } \\
\text { познавательного и творческого опыта }\end{array}$ & Система научных знаний, умений и навыков \\
\hline
\end{tabular}

правленный процесс воспитания и обучения, являющийся общественно значимым благом. Общественно значимым благом образование является в силу следующих причин: практически невозможно исключить человека из круга потребителей данного блага; получение образования одним человеком не должно уменьшать возможностей потребления его другим; данное благо неделимо, поскольку образование выступает как процесс.

2. Вместе с тем, в процесс реализации образования оказывается комплекс образовательных услуг. Под образовательной услугой следует понимать тот или иной объем учебной или научной информации, передаваемой субъекту в виде суммы знаний, умений и практических навыков для последующего применения. Кроме образовательных услуг и дополнительных образовательных услуг необходимо выделять сопутствующие услуги, которые не сопряжены непосредственно с образовательным процессом, но влияют на качество образования в целом.
3. Системный характер образования предопределяет тот факт, что образовательные услуги опосредуют, но не заменяют собой образование. Неделимость содержания образования, в том числе, неделимость физического, нравственного, политического, трудового и эстетического воспитания, не позволяет говорить о том, что повышение доступности учебной информации с помощью дистанционных образовательных технологий является процессом обобществления образования как блага.

4. Содержание образовательного процесса как комплекса услуг и как процесса воспитания и обучения, являющегося общественно значимым благом, должно в полной мере найти отражение в формах и средствах оценки качества образования. В частности, должны быть пересмотрены взгляды на систему применения в образовательной сфере такого управленческого инструментария как процессный менеджмент, TQM, EFGM, SWOT-анализ и сертификация по стандартам серии ISO-9001.

\section{Библиографический список}

1. едеральный закон «Об образовании в Российской Федерации» от 29.12.2012 № 273-ФЗ (последняя редакция) [Электронный ресурс]. URL: http://www.consultant.ru/document/cons_doc_LAW_140174/ (дата обращения: 10.01.2019).

2. Там же.

3. Лукашенко К.М. Высшее учебное заведение на рынке образовательных услуг: актуальные проблемы управления.- М.: Маркет ДС.-2012.-45 с.

4. Загайнова А.А. Основные проблемы рынка образовательных услуг в современной России // Научный журнал КубГАУ. - 2013. - № 91(07). - С. 2-10.

5. Щетинин В.П. Экономика образования: учебное пособие / В.П. Щетинин, Н.А. Хроменков, Б.С. Рябушкин.М.: Российское педагогическое агентство, 1998.- 305 с.

6. Хроменков Н.А. Экономика образования / Н.А. Хроменков, Б. Г. Рябушкин.- М.: Российское педагогическое агентство, 1998.- 269 с.

7. Величкович К.В. Экономическое содержание образовательной услуги сравнительный анализ концептуальных подходов / К. В. Величкович // Вестник БДУ. Сер.3. - 2007. - № 3.- С. 79-84.

8. Стрижов А. А Понятие качества образовательной услуги в условиях рыночных отношений /А.А. Стрижов // Стандарты и мониторинг в образовании. - 1999. - № 3.- С. 47-50. 
9. Налоговый кодекс Российской Федерации (НК РФ) [Электронный ресурс]. URL: http://www.consultant.ru/ document/cons_doc_LAW_19671/ (дата обращения: 10.01.2019).

10. Чекмарев В.В. Система экономических отношений в сфере образования: Научная монография / В.В. Чекмарев - Кострома: Издательство Костромского госпедуниверситета им. Н.А. Некрасова, 1998. - 400 с.

11. Вифлеемский А.Б. Роль образовательного комплекса в постиндустриальном обществе / А.Б. Вифлеемский // Вопросы экономики.-2002.- № 8.- С. 115-121.

12. Сыроваткина Т.Н. Основы экономики образования: учебное пособие / Т.Н. Сыроваткина.- Оренбург: ООО ИПК «Университет», 2013.- 152 с.

13. Скоробогатова Ю.А. Об определении понятия «образовательная услуга» / Ю.А. Скоробогатова // Известия Иркутской государственной экономической академии. - 2010. - № 5.- С. 254-257.

14. Еникеева С.Д. Рынок образовательных услуг и методы его регулирования: учебное пособие / С.Д. Еникеева. - М.: МАКС Пресс, 2011.- 108 c/

15. Антонова А.В. Рынок образовательных услуг: современные условия и тенденции развития: Автореф... дис. кан. экон. наук. - М.: 2012. -24 с..

16. Гражданский кодекс Российской Федерации (ГК РФ) [Электронный ресурс]. http://www.consultant.ru/ document/cons_doc_LAW_5142/ (дата обращения: 10.01.2019). 